Maternal Emotion Dysregulation and the Functional Organization of Preschoolers'

Emotional Expressions and Regulatory Behaviors

Grace Binion and Maureen Zalewski

University of Oregon

(C) 2017, American Psychological Association. This paper is not the copy of record and may not exactly replicate the final, authoritative version of the article. Please do not copy or cite without authors permission. The final article will be available, upon publication, via its DOI: 10.1037/emo0000319

Running head: MOTHER-PRESCHOOLER EMOTION REGULATION 


\begin{abstract}
While psychopathology in mothers is known to be a significant risk factor for child outcomes, less is known about how emotion dysregulation, a transdiagnostic feature that cuts across many diagnoses, shapes emotion-related parenting practices and the development of emotion regulation in offspring. Building upon previous research that examined the functional relations between emotions and regulatory actions in children, we sought to examine the association of maternal emotion dysregulation and emotion socialization with these functional links in an at risk community sample of mother-preschooler (children ages 36-60 months) dyads which over-sampled for mothers with elevated symptoms of Borderline Personality Disorder $(n=$ 68). We found that maternal emotion dysregulation was associated with children displaying more sadness and engaging in less problem solving during the Locked Box Task, which is designed to elicit anger. Maternal emotion dysregulation was also associated with children being more distracted and talking less in the context of sadness. Maternal non-supportive emotion socialization responses were associated with children engaging in more defiant behaviors throughout the task and using less problem solving in the context of happiness, while maternal supportive emotion socialization responses were associated with more play throughout the task and less talking in the context of sadness, above and beyond the effect of maternal emotion dysregulation. These findings indicate that maternal emotion dysregulation and non-supportive emotion socialization practices are both meaningfully associated with the development of aberrant patterns of emotional and behavioral responding during the preschool years.
\end{abstract} Keywords: Maternal emotion dysregulation, preschool, functional organization 


\section{Maternal emotion dysregulation and the functional organization of preschooler's emotional expressions and regulatory behaviors}

During the preschool period, children begin to engage in increasingly complex and volitional attempts at emotion regulation (Kopp, 1989; Tronick, 1989; Grolnick, Bridges, \& Connell, 1996). In this period, more automatic attempts at regulation (e.g. self-soothing) are replaced by independent efforts, such as problem solving (i.e. strategies which ameliorate sources of frustration) and information-gathering (Gilliom, Shaw, Beck, Schonberg, \& Lukon, 2002; Kopp, 1989). This shift in strategies is associated with more successful regulation of negative emotion both within the preschool years (Gilliom et al., 2002) and later in development (Shoda, Mischel, \& Peake, 1990). Emotion regulation capabilities in early childhood are also linked with positive social emotional and academic outcomes (Deham et al., 2003; Grazanio, Reaves, Keane, \& Calkins, 2007; Eisenberg et al., 1993; Fabes et al., 1999) and conversely, preschoolers who struggle with emotion regulation have greater internalizing and externalizing problems (Cole, Zahn-Waxler, Fox, Usher, \& Welsh, 1996; Eisenberg et al., 2001; Hill, Degnan, Calkins, \& Keane, 2006) that persist throughout development (Cole, Teti, \& Zahn-Waxler, 2003). For example, preschoolers' use of problem-focused coping strategies for negative emotions has been associated with fewer behavior problems and increased social competence (Blair, Denham, Kochankoff, \& Whipple, 2004). Given its crucial role in several aspects of development, theoretical frameworks have depicted how child and family characteristics influence the development of children's emotion regulation, with a particular emphasis on examining how children's emotion regulation may be a clinically important mechanism that confers risk for emerging psychopathology (Yap, Allen, \& Sheeber, 2007).

\section{Parent psychopathology and children's emotion regulation}


An important, yet understudied family-level characteristic influencing children's emotion regulation is psychopathology in parents. Psychopathology in parents is shown to be a robust risk factor for psychopathology in children, with evidence from a recent epidemiological study showing that the risk is nonspecific, meaning that children of parents with psychopathology have an elevated risk for developing any type of disorder (McLaughlin et al., 2012). Despite the strong link between parents' and children's psychopathology (Burstein, Stanger, Dumenci, 2012; McAdams et al., 2015) only a few studies have examined children's emotion regulation in the context of parental psychopathology. For example, Maughan and colleagues (2007) examined emotion regulation in preschool children of depressed and non-depressed mothers, finding that children whose mothers experienced clinical depression within two years of their child's birth were more dysregulated than their peers whose mothers had never been depressed. Similarly, in older children (7-12 year olds), Suveg, Shaffer, Morelen, \& Thomassin (2011) found that maternal psychopathology symptoms broadly were associated with children's poorer emotion regulation.

\section{Maternal emotion dysregulation and children's emotion regulation}

Increasingly, the adult psychopathology literature has emphasized transdiagnostic approaches over focusing only on discrete diagnoses (Mansell, Harvey, Watkins, \& Shafran, 2008). One clinically important transdiagnostic feature is emotion dysregulation (Aldao, Nolen-

Hoeksema, \& Schweizer, 2010; Gross, 1998). Emotion dysregulation is a central characteristic of many diagnoses including depression, anxiety, and trauma disorders (Kring, \& Sloan, 2009). Additionally, individuals with Borderline Personality Disorder have considerable difficulties with behavioral and cognitive efforts at regulating emotional experiences, resulting in extreme emotion dysregulation (Hughes, Crowell, Uyeji, \& Coan, 2012; Linehan, 1993). Individuals who 
are emotionally dysregulated struggle to respond effectively in the context of distressing emotion and instead use maladaptive coping strategies that manifest behaviorally or cognitively (Gross, 1998; Gross, 2002). Emotion dysregulation in parents may be a key mechanism explaining the high rates of transmission of psychopathology from parents to children. Further, difficulties with emotion regulation abilities in children may be one of the earliest signs of risk for emerging psychopathology (Rutherford, Wallace, Laurent \& Mayes, 2015). It is likely that this risk is transmitted by environmental (ex. parenting) and heritability factors. Specifically, negative emotionality and impulsivity are highly heritable traits that underlie emotion regulation (Plomin \& Stocker, 1989).

Regarding behavioral mechanisms, in addition to being a central characteristic of several forms of psychopathology, emotion regulation is critical for effective parenting (Dix, 1991). The majority of evidence to date has focused on mothers, noting that one central way in which maternal emotion regulation intersects with parenting is through maternal emotion socialization processes - the ways in which parents model, respond to, and coach children during emotional experiences (Breaux, Harvey, \& Lugo-Candelas, 2016; Crandall, Deater-Deckard, \& Riley, 2015; Denham, Zoller, \& Couchoud, 1994; Kiel, Viana, Tull, \& Gratz, 2016). Emotion socialization occurs in indirect ways, such as modeling or communicating expectations, as well as direct ways, such as providing coaching around children's emotional experiences or through parents' direct and contingent responses to children's emotions. Maternal emotion socialization behaviors communicate the appropriateness of children's emotional experiences, emotional expressions, and emotion regulatory behaviors. Such emotion socialization practices shape children's developing capacities to express and regulate their emotions in ways that help them achieve their goal in a socially or contextually appropriate manner (Klimes-Dougan et al., 2007; 
Sanders, Zeman, Poon, \& Miller, 2015). One particular form of emotion socialization, contingent responses to children's emotions, may be particularly important in shaping children's emotion regulation skills, as these parental responses provide immediate feedback to children regarding the appropriateness of their emotional response as well as information about the way they cope with different emotions (Eisenberg, Cumberland, \& Spinrad, 1998). Such contingent responses can be either supportive (i.e. validating) or non-supportive (i.e. dismissive). Evidence suggests that children have more intense negative emotions when their mothers frequently dismiss, minimize, punish, or respond with distress to children's emotions (Fabes, Leonard, Kupanoff, \& Martin, 2001). These unregulated emotional expressions are shown to confer risk for externalizing problems and are associated with decreased social competence (Tao, Zhou, \& Wang, 2010). Mothers who struggle to regulate their own emotions are at a disadvantage when attempting to respond to their children's emotions in ways that foster their growth in emotion regulation abilities (e.g. greater utilization of non-supportive emotional responses) (Bariola, Gullone, \& Hughes, 2011; Bariola, Hughes, \& Gullone, 2012). Thus, these practices may be one important way in which children's emotion regulation development is compromised by mothers' difficulties with emotion regulation. To date, only one study has examined the influence of maternal emotion regulation and emotion socialization practices on children's emotion regulation. Using a non-clinical sample of mother-preschooler dyads, Rogers, Halberstadt, Castro, MacCormack, and Garrett-Peters (2016) found that mothers' self-report of their own utilization of emotion suppression (an emotion regulation strategy generally considered ineffective) was negatively associated with teacher report of children's emotion regulation as scored on the Emotion Regulation Checklist. This study provides initial evidence that maternal emotion regulation strategies are directly related to children's emotion regulation. The present 
study builds upon this work by drawing from a sample of mother-child dyads recruited specifically for maternal emotion regulation difficulties and by utilizing an observational, microcoded measure of emotion regulation. Given the complexity of operationalizing emotion regulation, micro-coding of observational emotion regulation measures affords unique benefits distinct from more global parent or teacher report ratings.

\section{Functional perspective on emotion regulation}

As articulated in a seminal article on the scientific operationalization of emotion regulation during childhood, Cole, Martin, and Dennis (2004) stated the necessity of distinguishing between emotional displays from regulatory actions in order to avoid equating the expression of emotion with being dysregulated. Among several methodological recommendations, these authors advocate coding emotion and regulatory action separately and using temporal ordering to strengthen the inference that regulatory actions occur in response to emotional expression. These recommendations are aligned with a functional model of emotion theory which, as related to the current study goals, posits that particular situations or contexts are associated with discrete emotions (i.e. blocked goals elicit anger) and that one role of emotions is to motivate action (i.e. anger motivates overcoming blocked goal). Using this functional emotion theoretical framework, emotion dysregulation is understood as a) the elicitation of discrete emotions that are poorly suited to the context and b) the elicitation of actions which are not effective for managing the discrete emotional responses they are aimed at regulating. That is, emotion dysregulation is understood as disruption of contextually appropriate emotional responding, regulatory action, and the pairing of the two.

There is empirical support for the functional view of emotions in a preschool sample that examined emotions, regulatory actions and the pairing of emotion-regulatory actions during two 
different emotion eliciting contexts of frustration/challenge (Dennis, Cole, Wiggins, Cohen, \& Zalewski, 2009). Specifically, Dennis and colleagues (2009) used micro-coding to examine children's emotional displays, regulatory actions, and their pairing in two distinct contexts, finding that, across contexts, happiness and anger were associated with more regulatory actions compared to sadness. During the Locked Box Task, which represents a blocked goal, children exhibited more anger and such displays were associated with increased efforts at problem solving compared to other emotional experiences. Further, problem solving behaviors were the most commonly observed regulatory actions in this task. Together, these results suggest that, in typically developing children, anger and problem solving (and particularly the pairing of the two) can be expected to be observed most frequently and are understood to be adaptive. These results support a functional view of emotions, suggesting that emotional displays, regulatory actions, and the pairing of the two vary based on context and that these functional patterns are evident during the preschool period. Finally, this study illustrates the value of micro-coding children's emotion regulation, as such assessment is well-suited to capture one of the core deficits of emotion dysregulation - contingent, contextually appropriate responses to distress.

\section{Present Study Aims}

The present study examined associations between maternal emotion dysregulation, maternal emotion socialization, and children's emotion regulation during the Locked Box Task. In keeping with a functional view of emotions this study used the same 3 indicators of children's emotion regulation as Dennis and colleagues (2009): 1) emotional displays, 2) regulatory actions, and 3) emotion-action sequences.

Specifically, it was hypothesized that maternal emotion dysregulation severity would be associated with three indices of children's emotion regulation - 1) children displaying more 
frequent instances of negative emotions not typically elicited in a blocked goal task (sadness, fear); 2) children utilizing more regulatory actions which are less effective in a blocked-goal task (e.g. self-soothing)3) children displaying more frequent instances of emotion-action pairings not expected to be functionally linked (e.g. talking when happy). Additionally, it was hypothesized that maternal emotion socialization would be associated with these same three indices above and beyond the effect of maternal emotion dysregulation.

\section{Method}

\section{Participants}

Participants were 68 mothers and their 3-4-year-old children $(M=48, S D=7.6$ months $)$ recruited from various sources including a developmental database maintained by the psychology department, craigslist, and fliers placed at local mental health clinics. In order to ensure that a portion of the mothers had severe emotion dysregulation, mothers with elevated symptoms of Borderline Personality Disorder (BPD) were recruited, as one of the core features of BPD is emotion dysregulation. Thus, some of the recruitment adds explicitly advertised for mothers who experienced the following: fear of abandonment, difficulty controlling anger, being impulsive, having relationships with extreme ups and downs, and individuals who hurt themselves, in addition to the requirement of having custody of a 3- or 4-year old child. We over-recruited mothers with low income and low BPD severity to attempt to offset an anticipated association of low income with BPD. The distribution of the total family annual income of this sample represented in quartiles is: (1) less than $\$ 17,000$, (2) $\$ 17,000-\$ 29,000$, (3) $\$ 29,001$ $\$ 50,000$ and (4) \$50,000 or more. On the McLean Screening Instrument (Zanarini et al., 2003; range $0-9) 27 \%(n=18)$ endorsed $0-1$ symptoms, $24 \%$ endorsed $2-4$ symptoms $(n=16)$, and $49 \%$ endorsed 5 or more symptoms $(n=33)$. 
Families in which a child had a known developmental disability were excluded. Participants included 46\% $(n=31)$ girls. The racial and ethnic composition of the sample of children included 63.2\% European American, 5.9\% Latino or Hispanic, 1.5\% African American, 29.4\% multiple racial and ethnic backgrounds including individuals who identified their children as Asian American, American Indian, Native Hawaiian or Pacific Islander. The distribution of mothers' educational level included $6 \%$ mothers with some high school attainment, $4.5 \%$ completed high school, $35.8 \%$ with some college, $14.9 \%$ technical school or professional school, $26.9 \%$ college graduates, and $12 \%$ with post-graduate education. Sixty-two percent of mothers were married or had long-time partners, $25 \%$ were never married, $13 \%$ were separated, divorced or widowed and were single heads-of-household.

\section{Procedure}

Families were assessed in offices on a university campus. With approval by the Institutional Review Board, both mother's consent and child assent were secured prior to participating in a 2.5-hour session. Children completed assessments while mothers completed the questionnaires in an adjacent room. Next, mothers and children reunited for parent-child interactions. At the end, mothers were trained in home cortisol data collection although that data is not presented here. Families received $\$ 50$ for the laboratory visit.

\section{Measures}

Maternal emotion dysregulation. Maternal emotion dysregulation was assessed using the Difficulties with Emotion Regulation Scale (DERS; Gratz \& Roemer, 2004), a 36-item scale $(\alpha=.94)$ which asks participants to rate statements about their emotions and emotional states (i.e. "When I'm upset, I feel ashamed at myself for feeling that way") on a scale of 1-5, where 1 
is "almost never (0-10\%)" and 5 is "almost always (91-100\%)." Higher scores on this measure indicate greater emotion dysregulation, with a score of 70 reflecting a non-clinical community average and a score of 96 reflecting clinically significant emotion dysregulation (Gratz \& Roemer, 2004). In this sample, scores ranged from 40-125. Given the stratified sampling approach, DERS scores are here reported in quartiles: (1) < 51, (2) 52- 64, (3) 65- 78, and (4) > 78. Twelve percent of the present sample scored above the clinical cut-off.

Maternal emotion socialization. Maternal responses to children's negative emotions were assessed using the Coping with Children's Negative Emotions Scale (CCNES; Fabes, Eisenberg, \& Bernzweig, 1990), a 12-vignette questionnaire which measures parents' reactions to their child's negative emotions in various hypothetical scenarios. Mothers were asked to endorse the likelihood, on a scale from 1-7 (with 1 being "Very Unlikely" and 7 being "Very Likely"), with which they would utilize each of 6 potential responses to these situations. These responses are scored on 6 subscales - Distress Reactions, Punitive Reactions, Expressive Encouragement, Emotion-Focused Reactions, Problem-Focused Reactions, and Minimization with higher scores indicating greater utilization of that strategy. The 6 subscales can be grouped into 2 categories of responses - Supportive Responses (Expressive Encouragement, EmotionFocused Reactions, Problem-Focused reactions) and Non-Supportive Reactions (Distress Reactions, Punitive Reactions, and Minimization) - creating 2 summed scores. Given no hypotheses about unique contributions of each type of response, maternal emotion socialization was examined at the level of the 2 broad subscales. In the present sample, Supportive Responses $(\alpha=.89)$ scores ranged from 10.83-20.58 $(M=17.22, S D=2.43)$ while Non-Supportive Responses $(\alpha=.87)$ scores ranged from 3.58-15.50 $(M=7.42, S D=2.82)$, which represent typical mean responses for these subscales (Fabes, Poulin, Eisenberg, \& Madden-Derdich, 2002). 
Children's emotion regulation. Children's emotion regulation was derived from codes obtained from emotions, regulatory actions, and emotion-action sequences occurring during the Locked Box Task (Laboratory Temperament Assessment Battery; Goldsmith \& Rothbart, 1996), an ecologically valid frustration-eliciting task. Preschoolers were presented with several desirable toys and told to pick one that they wanted to take home. A research assistant then placed the selected toy in a transparent box, placed a lock on the box, and gave the child a ring of incorrect keys which they told the child would open the box. The research assistant then asked the child to work on opening the box for 2 minutes. Following this 2-minute period, the research assistant then provided the child with the correct key, said they made a mistake by giving the child the incorrect keys, and helped the child open the box and retrieve the toy. Three children did not complete the task and three tapes could not be coded due to technical errors.

\section{Data Coding}

Child emotional expressions and regulatory actions were coded by independent teams of coders. Both emotional expressions and regulatory actions were coded in time-synchronized 10second epochs. Following this, codes for emotion-action sequences were created.

Emotional expressions. Emotion expressions were coded using a coding system developed by Cole, Wiggins, Radzioch, and Pearl (2007) modified for 10-second epochs. A total of twelve 10-second epochs were observed and rated for the presence of four emotion states happy, sad, angry, or anxious - resulting in a maximum of 12 emotion codes across the 2-minute task, as only one emotion code was assigned per epoch. Table 1 provides a summary of the verbal, facial, and postural cues used to code each emotion. If no emotion cues were observed, coders assigned a neutral code to the epoch. In the instance multiple emotion cues were 
observed, those which were of greatest intensity and/or duration were coded. Following initial coding, totals were calculated for each emotional expression. Additionally, percentage values were calculated in order to assess the portion of the task each emotion was displayed. These values are presented in Table 2. Anger was the predominant emotional expression coded throughout the task.

Regulatory actions. Regulatory actions were coded using a manual developed for coding emotion regulation behaviors in preschoolers (Dennis, 2004). Actions were coded in 10-second epochs. Multiple behaviors within an epoch could be coded. The actions were:

1. Defiance/distress: inappropriate statements or behaviors such as crying, hitting, yelling, throwing keys and/or box, and refusing to engage in the task.

2. Problem solving: statements, questions, or behaviors which aid the child in acquisition of knowledge about or efforts to unlock the box. Questions include variants of "Which key is it?" and "How do you open it?" Statements include self-guiding prompts such as "It looks like it opens here," "Maybe this is the key," and "I'll try doing it this way." Behaviors include various strategies to open the box including examining the lock, trying keys in the lock, examining the box structure, and pulling on lock or box lid.

3. Distraction: attentional or behavioral shifts away from the box and/or task without any goal-directed purpose. These include walking away from the box, staring aimlessly away from the task, rattling or fidgeting with the keys in an aimless fashion, or putting head on table.

4. Self-soothe: comforting, often repetitious statements, questions, or behaviors not designed to elicit information about the task including repeated insistence the task cannot be completed ("It's too hard."), repeated pleas for help ("I need help."), and singing or humming to self. 
5. Play activity: actions or, less typically, statements, in which the child engages in goaldirected behavior which does not include work on the task. Such behaviors include engaging in pretend play with the keys, box, toy inside the box, or other toys in the room, singing ABCs, and attempting to engage in pretense play with the experimenter.

6. Talk: statements and questions which are not aimed at information gathering about the task or recruiting help in solving the task. These can vary widely and may be about the task ("This is like a puzzle!"), the selected toy ("The toy is in that box."), the research assistant ("Are you working?"), or the child and his or her family, friends, interests, opinions, etc.

As with emotions, frequency of each regulatory behavior observed over the course of the task was calculated. Because every behavior was coded as often as warranted both within epochs as well as across them, these ranges do not have an upper bound. Percentage values were calculated for each regulatory behavior. Problem solving behaviors constituted the majority of regulatory behaviors children used (Table 2).

Emotion-action sequences. While causality is not inferred, a functional view of emotions holds that, because emotions serve to motivate or support action, emotional displays which occur prior to or in conjunction with regulatory behaviors are most likely functionally related to those behaviors. Accordingly, actions which were preceded within the same 10 -second epoch by or observed concomitant with an emotional expression were assigned unique codes for that emotion-action pairing, such that every action was paired with an emotion code (or, in the case where no emotion was expressed, a "neutral" code). Coders were trained to ensure that regulatory actions were only paired with emotional expressions which began before or in the same second as the action. Totals for each of these emotion-action pairings were calculated by emotion category. Due to variability in number of regulatory actions exhibited as well as 
frequency of each emotion expression, percentage values were calculated. Values were computed such that each value represents a percentage of all emotion-action sequences for a given emotion category (e.g. Anger) coded with a given regulatory action (e.g. Problem Solve). For example, the Anger-Problem Solve variable was computed as follows:

$$
\text { Anger-Problem Solve }=\frac{\text { Number of Anger-Problem Solve Paired Codes }}{\text { Number of Total Anger-Action Paired Codes }}
$$

Interrater agreement. As stated previously, coding for emotional displays and regulatory behaviors was conducted by two separate coders. For each, coders were trained to an accuracy of $80 \%$ agreement with a master coder. Interrater reliability was estimated based on $17 \%$ of files which were randomly assigned. Kappa coefficients were calculated. The average Cohen's kappa for emotion coding was 0.79 ; the average Cohen's kappa for behavior coding was 0.81 , representing excellent agreement for both.

Missing Data. A total of six tapes could not be coded because of child non-compliance or technical error in which digital recordings could not be opened for coding. Children with missing data did not differ on key maternal variables: maternal emotion dysregulation missing $M$ $=70.4$, non-missing $M=68.28, t(65)=-.21, p=.84$; supportive maternal emotion socialization missing $M=17.83$, non-missing $M=17.17, t(65)=-.59, p=.56$; non-supportive maternal emotion socialization missing $M=8.03$, non-missing $M=7.37, t(65)=-.50, p=.62$; total family income missing $M=21,071$, non-missing $M=46,739, t(65)=1.00, p=.32$. All other children completed the task in its entirety, such that all epochs could be coded.

\section{Data Analysis Plan}


First, covariates were considered for inclusion in the models. Annual family income, child gender, and child age are related to children's emotion regulation (Raver, 2004) and were considered for inclusion as covariates. Associations between outcome variables and child gender ( $t$-test values ranged -1.55 to 1.36 , all $p \mathrm{~s}>.05$ ) and age (correlations ranged -.25 to .21 , all $p \mathrm{~s}$ $>.05$ ) were small and not significant and thus these were not included as covariates. Total family income was consistently associated with emotion regulation measures and was therefore included as a covariate for all models.

Next, in order to test the proposed associations, a series of regressions were run in which predictors were entered hierarchically. For each child emotion regulation dimension - emotion expression, regulatory action, and emotion-regulatory action pairing - a three-step regression series was conducted. Only emotion-regulatory action pairings which occurred with a mean frequency of $5 \%$ of the task (12 pairings) or greater were analyzed. In total, this three-step regression series was conducted for four emotional expressions, six regulatory actions, and 12 emotion-action pairings. Order of predictors entered was the same for each series, with the covariate, family annual income, entered at step 1, maternal emotion dysregulation in step 2, and maternal emotion socialization in step 3. For each step, unstandardized estimates (B), their standard errors (SE), and 95\% confidence intervals are presented to examine the unique contribution of each predictor. Additionally, R-squared is presented for each initial model and Rsquared change for each subsequent model step in order to evaluate the performance of each model as a whole.

Given the number of regression models tested, Bonferroni corrections were applied to reduce inflation of Type 1 error rate. For emotion regression models, this corrects significance criterion to $p<.01$, for behavior regression models, this corrects significance criterion to $p<.008$, 
and for emotion-action pairing models, this corrects criterion to $p<.006$. Due to the very conservative nature of these corrections, however, and the resultant depletion of power, results are presented both with and without corrections. All findings significant at $p<.05$ are discussed in the results section, with those which remained significant following application of Bonferroni corrections indicated in tabled results.

\section{Results}

Prior to testing hierarchical regression models, bivariate associations between predictor and outcome variables were examined in order to ensure the further testing of such models was appropriate. Maternal emotion dysregulation was associated with children displaying more sadness $r(62)=.32, p=.013$, engaging in more play activity $r(62)=.33, p=.01$, engaging in more self-soothing behaviors $r(62)=.37, p=.003$, and engaging in less problem-solving $r(62)=$ $-.34, p=.007$ during the Locked Box Task. Maternal supportive emotion socialization was associated with children engaging in less distraction regardless of concomitant emotional expression $r(62)=-.27, p=.035$ and with children engaging in less talking $r(39)=-.38, p=.019$ and distraction $r(38)=-.33, p=.045$ in the context of sadness. Maternal non-supportive emotion socialization was associated with children engaging in more defiance $r(62)=.30, p=.017$ ) and less problem solving $r(62)=-.26, p=.041$ overall and with children engaging in less problem solving in the context of happiness $r(37)=-.37, p=.025$. Given these associations, further testing of hierarchical models was appropriate.

\section{Emotion Display}

To examine children's emotional expressions, a series of regressions were run predicting the percentage of the task that a particular emotion was displayed (e.g. percentage of all emotion 
displays coded "Anger," percentage of all emotion displays coded "Happy”). Annual family income, maternal emotion dysregulation, and maternal emotion socialization were entered hierarchically into the model. Results for each step are presented in Table 3. Controlling for the effects of family income, maternal emotion dysregulation was associated with children displaying more sadness (percentage of the task coded Sadness) during the Locked Box Task. Maternal emotion socialization was not significant in any model predicting children's emotion displays. No models predicting children's displays of anxious, happy, or neutral emotions were significant.

\section{Regulatory Behaviors}

To examine children's use of regulatory actions a parallel set of regressions was run. Results of these regressions are reported in Table 4. Controlling for the effects of family income, maternal emotion dysregulation was associated with children using less problem solving and more self-soothing behaviors. In step 3, inclusion of maternal emotion socialization did not significantly improve either of these models. Maternal emotion dysregulation was also associated with greater play activity. Beyond the effects of maternal emotion dysregulation, maternal supportive emotion socialization responses, improved the model and significantly predicted children's greater play activity. Finally, non-supportive emotion socialization responses were associated with children engaging in more defiant behaviors throughout the task. No models predicting distraction or talk behaviors were significant.

\section{Emotion-Action Pairings}

In order to examine associations between maternal variables and children's utilization of regulatory actions in the context of certain emotional displays, a parallel series of regressions 
were run. Only emotion-action sequences with a mean frequency of 5\% or greater were examined (these are starred in Table 2). For each emotion-action sequence, multiple linear regressions paralleling the previous models were conducted. Results from these regressions are reported in Table 5 .

Greater maternal emotion dysregulation was associated with children talking less in the context of sadness. This suggests that when displaying sadness during the task, children of more dysregulated mothers were less likely to engage with or verbally express themselves to the experimenter. This association, while large in step 2, was only significant when maternal emotion socialization was included in the final step of the model. Greater maternal supportive emotion socialization responses were also associated with children talking less in the context of sadness. Maternal emotion dysregulation was further associated with greater distraction in the context of sadness, potentially suggesting disengagement from the task when sad. While this association becomes marginally significant when maternal emotion socialization is added to the model, the magnitude of association remained noteworthy. Finally, greater maternal nonsupportive emotion socialization responses were associated with less problem solving in the context of happiness, an association which was marginally significant.

\section{Discussion}

This study sought to examine the influence of maternal emotion dysregulation and emotion socialization on preschool children's emotional expressions, regulatory behaviors, and the functional pairing of emotions and actions during a blocked goal task designed to elicit anger. Broadly, maternal emotion dysregulation was associated with children's display of emotional and behavioral responses that would not be expected to emerge during a task specifically 
designed to elicit anger. Furthermore, this study provides evidence that while maternal emotion socialization was associated with children's emotion regulation, it did not serve as a mechanistic pathway explaining the relation between maternal emotion dysregulation and children's emotion regulation. Instead, both maternal emotion dysregulation and emotion socialization exerted independent effects on children's emotion regulation.

One key finding of the present study was that children whose mothers were more emotionally dysregulated displayed more sadness during the Locked Box Task, a task designed to elicit anger (frustration) by blocking a goal. In fact, previous work found that anger was the most frequently observed emotion during this task and, in contrast, displays of sadness were infrequent (Dennis et al, 2009). Similarly, within the current sample, anger was the emotional expression observed most frequently during the task. Thus, sadness when faced with a blocked goal represents an atypical emotional expression for the given context. Even though the task overall elicited anger most frequently, in both the zero-order correlations and at each hierarchical step, maternal emotion dysregulation was significantly associated with children's display of sadness. It is possible that this mismatch between context and elicited emotional response (sadness in response to a blocked goal) is indicative of learned helplessness. Learned helplessness is understood to manifest after repeated efforts to mitigate distress and improve one's situation are deemed impossible (Abramson, Seligman, \& Teasdale, 1978). Individuals who have developed this response may feel sadness when confronted with situations they believe to be out of their control (Nolen-Hoeksema, Girgus, \& Seligman, 1986). It is possible that maternal emotion dysregulation creates an environment wherein children frequently encounter situations that do not provide adequate support to help them solve problems. That is, maternal emotion dysregulation may reduce maternal responsivity (Havighurst, Wilson, Harley, Prior, \& 
Kehoe, 2010) or increase general chaos in the home (Crandall, Deater-Deckard, \& Riley, 2015) such that children are less likely to receive attentive, sensitive support when distressed or faced with a problem they do not know how to solve. Over time, children may learn that their environments and particularly their caregivers are unreliable or unresponsive to their needs and that persistence when faced with a blocked goal is futile. Thus, when confronted with a blocked goal, rather than responding with anger, children reared by emotionally dysregulated mothers may feel sadness instead.

It should be noted that only lower family income was associated with children's displays of anger. While anger was the most commonly expressed emotion in this task, no maternal variables were associated with anger displays. This suggests that the maternal risk factors of interest (emotion dysregulation and emotion socialization) may not increase the display of negative emotion, but rather convey risk though disruption of functional emotion-action organization, in that certain contexts (e.g. a blocked goal) are meant to elicit specific emotions (e.g. anger). In this sample, children of emotionally dysregulated mothers were more likely to exhibit negative emotion unexpected given the eliciting context (e.g. sadness).

Maternal emotion dysregulation was also associated with children's use of certain regulation strategies. Both in previous work as well as in the present study, when faced with a blocked goal, children typically respond with problem solving (Dennis et al., 2009). Maternal emotion dysregulation, however, was associated with children engaging in both increased play activity and less problem solving behaviors. Engaging in these types of regulatory behaviors may signal children's difficulty sustaining goal-directed activity. Problems maintaining focus on a goal is commonly observed in other contexts of risk such as poverty (Noble, McCambliss, \& Farah, 2007) and maltreatment (DePrince, Weinzierl, \& Combs, 2009). Thus, it appears maternal 
emotion dysregulation may represent a similar domain of risk, as children whose mothers were more dysregulated exhibited less on-task behavior aimed at problem solving.

A functional view of emotion theory holds that emotions motivate particular actions and that, broadly, psychopathology is in part defined by the inability to use effective regulation strategies to manage specific emotions. Micro-coding the emotion and action sequences provides a nuanced look into early signs of emotion dysregulation, in that some children may use regulatory behaviors that do not functionally correspond with particular emotions. In this study, we found that maternal emotion dysregulation was associated with children engaging in less talk (both to themselves and with the research assistant) and increased distraction (attentional or behavioral orientation away from the task) in the context of feeling sad. Previous work has suggested that task-oriented approach behaviors in response to a blocked goal are less often associated with displays of sadness relative to displays of anger (Dennis et al., 2009). In Dennis and colleagues' 2009 study, however, the regulatory action most often displayed following sadness was also problem solving. Thus, while anger appears to promote more problem solving than sadness, sadness also predominantly supports efforts at problem solving in a typically developing sample. The present study builds upon this by suggesting that displays of sadness may be particularly difficult for children of emotionally dysregulated mothers, as these children were both more likely to display sadness (which is uncommon when facing a blocked goal) and less likely to engage in functional task-related behaviors when displaying sadness. Together, these findings suggest that maternal emotion dysregulation may impart difficulty with persistence in the face of a blocked goal, as manifest in aberrant emotional displays, behavioral responses, and nuanced emotion-action pairings. 
In contrast to our expectations, maternal socialization of emotion did not explain the relation of maternal emotion dysregulation with children's emotion regulation. The absence of evidence that emotion socialization explained variance in children's emotion regulation beyond maternal emotion dysregulation provided no suggestion that mediation analyses were warranted. Rather, it appears that maternal emotion socialization was independently related to children's emotion regulation. While prevailing theory suggests that maternal emotion regulation (or dysregulation) is related to children's emotion regulation through maternal emotion socialization practices, empirical evidence has actually yielded mixed support in regards to this mechanistic model. Though some studies find evidence of this mechanistic relation (Havighurst et al., 2010), others have not (Hoffman, Crnic, \& Baker, 2006). It may be that both of these maternal factors represent independent pathways of influence on children's capacity to regulate their own emotions.

If it is not mothers' contingent responding to children's emotions, what factors may explain the relation between maternal emotion dysregulation and children's emotion regulation? Although speculative, several factors may explain this relation. Family chaos or other cumulative risk factors are associated with parental emotion regulation difficulties (Crandall et al., 2015) and these factors are also related to poor development of emotion regulation in children. Additionally, maternal modeling of emotion regulation is likely to be compromised in mothers who struggle to regulate their own emotions and it is possible that explicit child-directed messages (coaching, instruction) regarding the appropriateness of various emotional states and regulatory strategies may be altered in ways which foster aberrant development (Bariola et al., 2011). Finally, it is likely that genetic heritability contributes to the association between mothers' and children's emotion regulation. It is believed, however, that emotion regulation is multiply 
determined from temperament (which is understood to be heritable) and socialization, though the precise contribution of each of these factors has yet to be established (Yap, Allen, \& Scheeber, 2007).

Even though these other factors may explain the link between mothers' and children's emotion regulation, it is possible that maternal emotion socialization remains an important mechanism explaining this link. The current study focused on mothers' responses to children's emotional displays and did not measure other domains of emotion socialization such as maternal emotional displays and regulatory behaviors or mothers' overt emotion-related communication (coaching, discussion, etc.). Thus it remains possible that while we did not find support for a mechanistic model, other aspects of emotion socialization could potentially explain the association between mothers' and children's emotion regulation. Greater research is needed to comprehensively examine these pathways.

Strengths of this study include the use of independent systems for micro-coding children's emotions versus regulatory actions (Cole, Martin, \& Dennis, 2004). Micro-coding, in contrast to global coding systems, afforded detection of subtle and perhaps early signs of dysregulation in which children were employing less effective regulatory actions to manage emotional states. An additional strength of this study pertains to the sample used to test the study hypotheses. Specifically, mothers in this sample represented the full range of emotion dysregulation severity, with significant representation at the severe level. This recruitment strategy permits a more rigorous test of the relation between mothers' and children's emotion regulation which extends beyond the current literature that has predominantly used either lower risk or extremely at risk samples (Bariola et al., 2011). Moreover, while a modestly sized sample, the present sample is among the larger datasets that have recruited for mothers with Borderline 
Personality Disorder, and moreover, maintained a narrow developmental period in which emotion regulation rapidly develops (Eyden, Winsper, Wolke, Broome, \& MacCallum, 2016).

This study has four key limitations that should be considered when designing future studies pertaining to these questions. The first major limitation of this study comes from the cross-sectional design in which the potential for bi-directional associations cannot be tested. It is possible that children who are frequently or more intensely emotionally dysregulated elicit less supportive parenting over time and may even exacerbate mothers' dysregulation because of the stress inherent in parenting a child with a difficult temperament (Crockenberg \& Leerkes, 2003; Muslow, Caldera, Pursley, Reifman, \& Huston, 2002). In fact, it is possible that, owing in part to genetic heritability, children of more emotionally dysregulated mothers are themselves more dysregulated (Saudino, 2005). Despite this limitation, the current study represents an important first step as it provides support that maternal and children's emotion regulation are related, laying the requisite groundwork for determining each member of the dyad's contribution to the observed relation. A second limitation is the possibility that mothers with psychopathology may not be accurate reporters on aspects of their parenting. Though a recent study found that mothers with Borderline Personality Disorder provided reports which corresponded with observational measures of infant negative emotionality (Whalen, Kiel, Tull, Latzman, \& Gratz, 2015), there has been no such parallel examination between observed and self-report of parenting behaviors such as emotion socialization. Ideally, future work should employ a multimethod assessment of emotion socialization. A third limitation is the modest sample size used and related potential power issues. While a sample of 68 is a sizable for a study sampling mothers with Borderline Personality Disorder who have a preschooler, it is not large enough to yield high power to detect small effects. While power was adequate ( $\geq 85 \%)$ to detect medium effects in the presented 
regression models, this study was underpowered to detect small effects. Thus, it is possible that some of the unexpected results, such as the lack of an indirect effect through maternal emotion socialization, could have resulted from power issues. The final limitation is that the conclusions related to the mechanistic framing of this study are not causal. This study was unable to determine how heritability, specifically relating to traits of impulsivity and negative affectivity, which underlie emotion dysregulation, may better explain the relation between mother's and children's emotion regulation, such that socialization factors are less relevant. While a less commonly employed design, causal inference could be strengthened through experimental manipulation of mothers' emotion regulation or emotion socialization using interventions that target these constructs (e.g. Dialectical Behavior Therapy, emotion coaching interventions) in order to quantify the extent of changes in children's emotion regulation that occur as maternal emotion regulation improves. Future work should consider using such designs, which improve over the majority of tests which rely on correlational designs.

In sum, the present study provides support that emotion dysregulation, a transdiagnostic feature of several forms of psychopathology, in mothers is a risk factor for children's emerging emotion regulation abilities. Children of emotionally dysregulated mothers respond to frustrating situations with greater sadness and utilize less effective strategies for regulating their emotional experiences. The differences observed in the functional pairing of emotions and regulatory actions may hint at early signs of children's emotion dysregulation, which is a significant risk factor for subsequent psychopathology. Taken together, this study supports the need for interventions that may target these dually dysregulated dyads. 


\section{References}

Abramson, L. Y., Seligman, M. E. P., \& Teasdale, J. D. (1978). Learned helplessness in humans and reformulation. Journal of Abnormal Psychology, 87(1), 49-74.

Aldao, A., Nolen-Hoeksema, S., \& Schweizer, S. (2010). Emotion-regulation strategies across psychopathology: A meta-analytic review. Clinical Psychology Review, 30(2), 217-237. http://dx.doi.org/10.1016/j.cpr.2009.11.004

Bariola, E., Gullone, E., \& Hughes, E. K. (2011). Child and adolescent emotion regulation: The role of parental emotion regulation and expression. Clinical Child and Family Psychology Review, 14(2), 198-212. doi:10.1007/s10567-011-0092-5

Bariola, E., Hughes, E. K., \& Gullone, E. (2012). Relationships between parent and child emotion regulation strategy use: A brief report. Journal of Child and Family Studies, 21(3), 443-448. http://doi.org/10.1007/s10826-011-9497-5

Barnow, S., Spitzer, C., Grabe, H. J., Kessler, C., \& Freyberger, H. J. (2006). Individual characteristics, familial experience, and psychopathology in children of mothers with borderline personality disorder. Journal of the American Academy of Child \& Adolescent Psychiatry, 45(8), 965-972. http://doi.org/10.1097/01.chi.0000222790.41853.b9

Belsky, J. (1984). The determinants of parenting: A process model. Child Development, 55(1), 83-96. 
Blair, K. A., Denham, S. A., Kochanoff, A., \& Whipple, B. (2004). Playing it cool:

Temperament, emotion regulation, and social behavior in preschoolers. Journal of School Psychology, 42(6), 419-443.

Breaux, R. P., Harvey, E. A., \& Lugo-Candelas, C. I. (2016). The role of parent psychopathology in emotion socialization. Journal of Abnormal Child Psychology, 44(4), 731-743. http://doi.org/10.1007/s10802-015-0062-3

Buckholdt, K. E., Parra, G. R., \& Jobe-Shields, L. (2014). Intergenerational transmission of emotion dysregulation through parental invalidation of emotions: Implications for adolescent internalizing and externalizing behaviors. Journal of Child and Family Studies, 23(2014), 324-332. http://doi.org/10.1007/s10826-013-9768-4

Burstein, M., Stanger, C., \& Dumenci, L. (2012). Relations between parent psychopathology family functioning and adolescent problems in substance-abusing families: Disaggregating the effects of parent gender. Child Psychiatry and Human Development, 43(4), 631-647. http://doi.org/10.1007/s10578-012-0288-z

Campos, J. J., Campos, R. G., \& Barrett, K. C. (1989). Emergent themes in the study of emotional development and emotion regulation. Developmental Psychology, 25(3), 394402. http://doi.org/10.1037/0012-1649.25.3.394

Cole, P., Zahn-Waxler, C., Fox, N., Usher, B., \& Welsh, J. (1996). Individual differences in emotion regulation and behavior problems in preschool children. Journal of Abnormal Psychology, 105(4), 518-529. 
Cole, P. M., Teti, L. O., \& Zahn-Waxler, C. (2003). Mutual emotion regulation and the stability of conduct problems between preschool and early school age. Development and Psychopathology, 15, 1-18. http://doi.org/10.1017/S0954579403000014

Cole, P. M., Martin, S. E., \& Dennis, T. a. (2004). Emotion regulation as a scientific construct: Methodological challenges and directions for child development research. Child Development, 75(2), 317-333. http://doi.org/10.1111/j.1467-8624.2004.00673.x

Cole, P. M., Wiggins, C. N., Radzioch, A. M., \& Pearl, A. M. (2007). D.O.T.S. emotion coding system. Unpublished research manual, Department of Psychology, Pennsylvania State University, Philadelphia, Pennsylvania.

Crandall, A., Deater-Deckard, K., \& Riley, A. W. (2015). Maternal emotion and cognitive control capacities and parenting: A conceptual framework. Developmental Review, 36, 105126. http://doi.org/10.1016/j.dr.2015.01.004

Crockenberg, S. \& Leerkes, E. (2003). Infant negative emotionality, caregiving, and family relationships. In Crouter, A. C. \& Booth, A. (Eds.), Children's influence on family dynamics: The neglected side of family relationships (57-78). Mahwah, NJ: Lawrence Erlbaum Associates.

Denham, S. A., Zoller, D., \& Couchoud, E. A. (1994). Socialization of preschoolers' emotion understanding. Developmental Psychology, 30(6), 928-936. http://doi.org/10.1037/00121649.30.6.928 
Denham, S. A., Blair, K. A., DeMulder, E., Levitas, J., Sawyer, K., Auerbach-Major, S., \& Queenan, P. (2003). Preschool emotional competence: Pathway to social competence? Child Development, 74(1), 238-256. doi:10.1111/1467-8624.00533

Dennis, T.A. (2004). Manual for coding child emotion regulation behaviors. Unpublished research manual, Hunter College, City University of New York, New York, New York.

Dennis, T. A., Cole, P. M., Wiggins, C. N., Cohen, L. H., \& Zalewski, M. (2009). The functional organization of preschool-age children's emotion expressions and actions in challenging situations. Emotion, 9(4), 520-530. doi:10.1037/a0016514

DePrince, A. P., Weinzierl, K. M., \& Combs, M. D. (2009). Executive function performance and trauma exposure in a community sample of children. Child Abuse and Neglect, 33(6), 353361. doi:10.1016/j.chiabu.2008.08.002

Dix, T. (1991). The affective organization of parenting: Adaptive and maladaptative processes. Psychological Bulletin, 110(1), 3-25. http://dx.doi.org/10.1037/0033$\underline{2909.110 .1 .3}$

Eisenberg, N., Fabes, R. A., Bernzweig, J., Karbon, M., Poulin, R., \& Hanish, L. (1993). The relations of emotionality and regulation to preschoolers' social skills and sociometric status. Child Development, 64(5), 1418-1438. doi:10.2307/1131543

Eisenberg, N., Fabes, R. a, Murphy, B., Maszk, P., Smith, M., \& Karbon, M. (1995). The role of emotionality and regulation in children's social functioning: A longitudinal study. Child Development, 66(5), 1360-1384. 
Eisenberg, N., Cumberland, A., \& Spinrad, T. L. (1998). Parental socialization of emotion. Psychological Inquiry, 9(5), 241-273. doi:10.1207/s15327965pli0904

Eisenberg, N., Fabes, R. a, Guthrie, I. K., \& Reiser, M. (2000). Dispositional emotionality and regulation: Their role in predicting quality of social functioning. Journal of Personality and Social Psychology, 78(1), 136-157. doi:10.1037/0022-3514.78.1.136

Eisenberg, N., Cumberland, A., Spinrad, T. L., Fabes, R. A., Shepard, S. A., Reiser, M., ... Guthrie, I. K. (2001). The relations of regulation and emotionality to children's externalizing and internalizing problem behavior. Child Development, 72(4), 1112-1134. http://dx.doi.org/10.1111/1467-8624.00337

Eyden, J., Winsper, C., Wolke, D., Broome, M. R., \& MacCallum, F. (2016). A systematic review of the parenting and outcomes experienced by offspring of mothers with borderline personality pathology: Potential mechanisms and clinical implications. Clinical Psychology Review, 47, 85-105. http://doi.org/10.1016/j.cpr.2016.04.002

Fabes, R. A., Eisenberg, N., \& Bernzweig, J. (1990). Coping with children's negative emotions scale (CCNES): Description and scoring. Tempe, AZ: Arizona State University.

Fabes, R. A., Eisenberg, N., Jones, S., Smith, M., Guthrie, I., Shepard, S., \& Friedman, J. (1999). Regulation, emotionality, and preschoolers' socially competent peer interactions between their own desires and interests. Child Development, 70(2), 432-442. 
Fabes, R. A., Leonard, S. A., Kupanoff, K., \& Martin, C. L. (2001). Parental coping with children's negative emotions: Relations with children's emotional and social responding. Child Development, 72(3), 907-920.

Fabes, R., Poulin, R., Eisenberg, N., \& Madden-Derdich, D. A. (2002). Children's emotional regulation and social competence in middle childhood: The role of maternal and paternal interactive style. Marriage \& Family Review, 32(3-4), 285-310. http://doi.org/10.1300/J002v34n03

Gilliom, M., Shaw, D. S., Beck, J. E., Schonberg, M. A., \& Lukon, J. L. (2002). Anger regulation in disadvantaged preschool boys: Strategies, antecedents, and the development of self-control. Developmental Psychology, 38, 222-235.

Goldsmith, H. H., \& Rothbart, M. K. (1996). The Laboratory Temperament Assessment Battery (LabTAB): Locomotor version 3.0 technical manual. Department of Psychology, University of Wisconsin, Madison.

Gratz, K. L., \& Roemer, L. (2004). Multidimensional assessment of emotion regulation and dysregulation: Development, factor structure, and initial validation of the difficulties in emotion regulation scale. Journal of Psychopathology and Behavioral Assessment, 26(1), 41-54. http://doi.org/10.1023/B:JOBA.0000007455.08539.94

Graziano, P. A., Reavis, R. D., Keane, S. P., \& Calkins, S. D. (2007). The role of emotion regulation in children's early academic success. Journal of School Psychology, 45(1), 3-19. http://doi.org/10.1016/j.jsp.2006.09.002 
Grolnick, W. S., Bridges, L. J., \& Connell, J. P. (1996). Emotion regulation in two-year-olds: Strategies and emotional expression in four contexts. Child Development, 67(3), 928-941. http://doi.org/10.2307/1131871

Gross, J. J. (1998). The emerging field of emotion regulation: an integrative review. Review of General Psychology, 2(5), 271-299. http://doi.org/10.1017.S0048577201393198

Gross, J. (2002). Emotion regulation (reappraisal and suppression): Affective, cognitive, and social consequences. Psychophysiology, 39(3), 281-291. http://doi.org/10.1017.S0048577201393198

Havighurst, S. S., Wilson, K. R., Harley, A. E., Prior, M. R., \& Kehoe, C. (2010). Tuning in to Kids: Improving emotion socialization practices in parents of preschool children-findings from a community trial. Journal of Child Psychology and Psychiatry and Allied Disciplines, 51(12), 1342-1350. http://doi.org/10.1111/j.1469-7610.2010.02303.x

Hill, A. L., Degnan, K. A., Calkins, S. D., \& Keane, S. P. (2006). Profiles of externalizing behavior problems for boys and girls across preschool: The roles of emotion regulation and inattention. Developmental Psychology, 42(5), 913-928. http://doi.org/10.1037/0012-

\section{$\underline{1649.42 .5 .913}$}

Hoffman, C., Crnic, K. A., \& Baker, J. K. (2006). Maternal depression and parenting: Implications for children's emergent emotion regulation and behavioral functioning. Parenting: Science and Practice, 6(4), 271-295. 
Howard Sharp, K. M., Cohen, R., Kitzmann, K. M., \& Parra, G. R. (2015). Mechanisms mediating children's perceived maternal nonsupportive reactions to sadness and children's social and emotional functioning. Journal of Child and Family Studies, 25(2), 367-380.

\section{http://doi.org/10.1007/s10826-015-0240-5}

Hughes, A. E., Crowell, S. E., Uyeji, L., \& Coan, J. A. (2012). A developmental neuroscience of borderline pathology: Emotion dysregulation and social baseline theory. Journal of Abnormal Child Psychology, 40(1), 21-33.

Hughes, E. K., \& Gullone, E. (2010). Parent emotion socialisation practices and their associations with personality and emotion regulation. Personality and Individual Differences, 49(7), 694-699. http://doi.org/10.1016/j.paid.2010.05.042

Kiel, E. J., Viana, A. G., Tull, M. T., \& Gratz, K. L. (2016). Emotion socialization strategies of mothers with borderline personality disorder symptoms: The role of maternal emotion regulation and interactions with infant temperament. Journal of Personality Disorders, 118.

Klimes-Dougan, B., Brand, A. E., Zahn-Waxler, C., Usher, B., Hastings, P. D., Kendziora, K., \& Garside, R. B. (2007). Parental emotion socialization in adolescence: Differences in sex, age and problem status. Social Development, 16(2), 326-342. http://doi.org/10.1111/j.14679507.2007.00387.x

Kopp, C. B. (1989). Regulation of distress and negative emotions: A developmental view. Developmental Psychology, 25(3), 343-354. http://doi.org/10.1037/0012-1649.25.3.343 
Krause, E. D., Mendelson, T., \& Lynch, T. R. (2003). Childhood emotional invalidation and adult psychological distress: the mediating role of emotional inhibition. Child Abuse \& Neglect, 27(2), 199-213. doi:10.1016/S0145-2134(02)00536-7

Kring, A. M., \& Sloan, D. M. (Eds.). (2009). Emotion regulation and psychopathology: A transdiagnostic approach to etiology and treatment. New York, NY: Guilford Press.

Linehan, M. M. (1993). Cognitive behavioral therapy of borderline personality disorder (Vol. 51). New York: Guilford Press.

Mansell, W., Harvey, A., Watkins, E. R., \& Shafran, R. (2008). Cognitive behavioral processes across psychological disorders: A review of the utility and validity of the transdiagnostic approach. International Journal of Cognitive Therapy, 1(3), 181-191.

Maughan, A., Cicchetti, D., Toth, S. L., \& Rogosch, F. A. (2007). Early-occurring maternal depression and maternal negativity in predicting young children's emotion regulation and socioemotional difficulties. Journal of Abnormal Child Psychology, 35(5), 685-703. http://doi.org/10.1007/s10802-007-9129-0

McAdams, T. A., Rijsdijk, F. V, Neiderhiser, J. M., Narusyte, J., Shaw, D. S., Natsuaki, M. N., ... Eley, T. C. (2015). The relationship between parental depressive symptoms and offspring psychopathology: evidence from a children-of-twins study and an adoption study. Psychological Medicine, 45(12), 2583-2594. doi:10.1017/s0033291715000501

McLaughlin, K. A., Gadermann, A. M., Hwang, I., Sampson, N. A., Al-Hamzawi, A., Andrade, L. H., ... \& Caldas-de-Almeida, J. M. (2012). Parent psychopathology and offspring mental 
disorders: Results from the WHO world mental health surveys. The British Journal of Psychiatry, 200, 290-299.

Morris, A. S., Silk, J. S., Steinberg, L., \& Robinson, L. R. (2007). The role of the family context in the development of emotion regulation. Social Development, 16(2), 361-388. doi: 10.1111/j.1467-9507.2007.00389.x.The

Muslow, M., Caledera, Y. M., Pursley, M., Reifman, A., \& Huston, A. C. (2002). Multilevel factors influencing maternal stress during the first three years. Journal of Marriage and Family, 64(4), 944-956.

Noble, K. G., McCandliss, B. D., \& Farah, M. J. (2007). Socioeconomic gradients predict individual differences in neurocognitive abilities. Developmental Science, 10(4), 464-480. doi:10.1111/j.1467-7687.2007.00600.x

Nolen-Hoeksema, S., Girgus, J. S., \& Seligman, M. E. (1986). Learned helplessness in children: A longitudinal study of depression, achievement, and explanatory style. Journal of personality and social psychology, 51(2), 435-442. http://dx.doi.org/10.1037/0022$\underline{3514.51 .2 .435}$

Plomin, R., \& Stocker, C. (1989). Behavioral genetics and emotionality. In J. S. Reznick (Ed.), Perspectives on behavioral inhibition (pp. 219-240). Chicago: University of Chicago Press.

Rogers, M. L., Halberstadt, A. G., Castro, V. L., MacCormack, J. K., \& Garrett-Peters, P. (2016). Maternal emotion socialization differentially predicts third-grade children's emotion regulation and lability. Emotion, 16(2), 280-291. http://dx.doi.org/10.1037/emo0000142 
Rutherford, H. J., Wallace, N. S., Laurent, H. K., \& Mayes, L. C. (2015). Emotion regulation in parenthood. Developmental Review, 36, 1-14.

Sanders, W., Zeman, J., Poon, J., \& Miller, R. (2015). Child regulation of negative emotions and depressive symptoms: The moderating role of parental emotion socialization. Journal of Child and Family Studies, 24(2), 402-415. doi:10.1007/s10826-013-9850-y

Saudino, K. J. (2005). Behavioral Genetics and Child Temperament. Journal of Developmental and Behavioral Pediatrics, 26(3), 214-223.

Shoda, Y., Mischel, W., \& Peake, P. K. (1990). Predicting adolescent cognitive and selfregulatory competencies from preschool delay of gratification: Identifying diagnostic conditions. Developmental Psychology, 26, 978-986.

Stepp, S. D., Whalen, D. J., Pilkonis, P. a., Hipwell, A. E., \& Levine, M. D. (2012). Children of mothers with borderline personality disorder: Identifying parenting behaviors as potential targets for intervention. Personality Disorders: Theory, Research, and Treatment, 3(1), 7691. http://doi.org/10.1037/a0023081

Suveg, C., Shaffer, A., Morelen, D., \& Thomassin, K. (2011). Links between maternal and child psychopathology symptoms: Mediation through child emotion regulation and moderation through maternal behavior. Child Psychiatry and Human Development, 42(5), 507-520. $\underline{\text { doi.10.1007/s 10578-011-0223-8 }}$ 
Tao, A., Zhou, Q., \& Wang, Y. (2010). Parental reactions to children's negative emotions: Prospective relations to Chinese children's psychological adjustment. Journal of Family Psychology, 24(2), 135-144. dx.doi.10.1037/a0018974

Tronick, E. Z. (1989). Emotions and emotional communication in infants. The American Psychologist, 44(2), 112-9. doi.10.1037/0003-066X.44.2.112

Whalen, D. J., Kiel, E. J., Tull, M. T., Latzman, R. D., \& Gratz, K. L. (2015). Maternal borderline personality disorder symptoms and convergence between observed and reported infant negative emotional expressions. Personality Disorders, 6(3), 229-238. doi:10.1038/nbt.3121.ChIP-nexus

Yap, M. B. H., Allen, N. B., \& Sheeber, L. (2007). Using an emotion regulation framework to understand the role of temperament and family processes in risk for adolescent depressive disorders. Clinical Child and Family Psychology, 10(2), 180-196.

Yap, M. B. H., Allen, N. B., \& Ladouceur, C. D., (2008). Maternal socialization of positive affect: The impact of invalidation on adolescent emotion regulation and depressive symptomatology. Child Development, 79(5), 1415-1431.

Zanarini, M. C., Vujanovic, A. A., Parachini, E. A., Boulanger, J. L., Frankenburg, F. R., \& Hennen, J. (2003). A screening measure for BPD: The McLean screening instrument for borderline personality disorder (MSI-BPD). Journal of personality disorders, 17(6), 568573. 
Zeman, J., Shipman, K., \& Suveg, C. (2002). Anger and sadness regulation: predictions to internalizing and externalizing symptoms in children. Journal of Cinical Child and Adolescent Psychology, 31(3), 393-398. http://doi.org/10.1207/S15374424JCCP3103_11 
Table 1

Cues Used for Emotion Coding

\begin{tabular}{|c|c|c|c|}
\hline \multirow[b]{2}{*}{ Emotion } & \multicolumn{3}{|c|}{ Cue } \\
\hline & Postural & Facial & Vocal \\
\hline Happy & $\begin{array}{l}\text { Little tension in body, relaxed } \\
\text { shoulders and chest, arms } \\
\text { raised in excitement }\end{array}$ & $\begin{array}{l}\text { Smiling, smooth forehead, upturned } \\
\text { corners of mouth, crinkling in } \\
\text { corners of eyes }\end{array}$ & $\begin{array}{l}\text { Light, lilting tone, higher and/or } \\
\text { louder pitch, laughter, } \\
\text { humming }\end{array}$ \\
\hline Sad & $\begin{array}{l}\text { Drooping head, slumped } \\
\text { shoulders and/or body, eye } \\
\text { rubbing to mask tears }\end{array}$ & $\begin{array}{l}\text { Lip corners pulled down, quivering or } \\
\text { loose bottom lip, drooping eyes, } \\
\text { oblique-shaped brow }\end{array}$ & $\begin{array}{l}\text { Lowered volume, whining } \\
\text { vocalizations without protest }\end{array}$ \\
\hline Angry & $\begin{array}{l}\text { Arms akimbo, finger wagging or } \\
\text { jabbing }\end{array}$ & $\begin{array}{l}\text { Furrowed brow, eyes narrowed, } \\
\text { clenched or set jaw, pressed or } \\
\text { tightened lips }\end{array}$ & $\begin{array}{l}\text { Harsh vocal tone, louder and/or } \\
\text { deeper pitch, whining } \\
\text { vocalizations with protest } \\
\text { quality }\end{array}$ \\
\hline Anxious & $\begin{array}{l}\text { Jittery, repeated hand or foot } \\
\text { movement, stiff upper body, } \\
\text { raised shoulders }\end{array}$ & $\begin{array}{l}\text { Furrowed brow, raised eyelids, lips } \\
\text { retracted, lip-biting, darting } \\
\text { glances }\end{array}$ & $\begin{array}{l}\text { Strained or stressed voice, shaky } \\
\text { or tight tone }\end{array}$ \\
\hline
\end{tabular}


Table 2

Coded Emotions, Actions, and Emotion-Action Sequences

\begin{tabular}{|c|c|c|c|}
\hline \multirow[b]{2}{*}{ Observation } & \multicolumn{3}{|c|}{ Locked-Box Task } \\
\hline & $M$ Frequency & Range & $\%$ \\
\hline \multicolumn{4}{|l|}{ Emotion expression episodes } \\
\hline Neutral & $4.84(2.95)$ & $0-11$ & $40.32(24.57)$ \\
\hline Happy & $1.82(2.23)$ & $0-9$ & $15.19(18.57)$ \\
\hline Sadness & $1.47(1.64)$ & $0-7$ & $12.23(13.64)$ \\
\hline Anger & $3.40(2.71)$ & $0-10$ & $28.36(22.56)$ \\
\hline Anxiety & $0.35(1.26)$ & $0-9$ & $2.96(10.46)$ \\
\hline \multicolumn{4}{|l|}{ Actions } \\
\hline Defiance & $0.15(0.70)$ & $0-5$ & $0.78(3.50)$ \\
\hline Problem Solve & $15.63(4.21)$ & $4-26$ & $75.17(17.97)$ \\
\hline Distract & $1.48(2.00)$ & $0-8$ & $7.42(10.88)$ \\
\hline Self-Soothe & $0.62(1.10)$ & $0-5$ & $2.52(4.37)$ \\
\hline Play Activity & $0.18(0.74)$ & $0-5$ & $0.67(2.64)$ \\
\hline Talk & $3.29(3.49)$ & $0-15$ & $13.43(12.25)$ \\
\hline \multicolumn{4}{|l|}{ Emotion-action sequences } \\
\hline Neutral-Defiance & $0.04(0.38)$ & $0-3$ & $0.75(0.57)$ \\
\hline Neutral-Problem Solve & $5.74(4.02)$ & $0-16$ & $80.01(26.80)$ \\
\hline Neutral-Distract & $0.58(1.05)$ & $0-4$ & $8.44(18.41)$ \\
\hline Neutral-Self Soothe & $0.08(0.33)$ & $0-2$ & $0.89(4.26)$ \\
\hline Neutral-Play Activity & $0.05(0.28)$ & $0-2$ & $1.02(5.47)$ \\
\hline Neutral-Talk & $0.48(0.84)$ & $0-4$ & $8.88(15.87)$ \\
\hline Happy-Defiance & $0.02(0.13)$ & $0-1$ & $1.32(8.11)$ \\
\hline Happy-Problem Solve* & $2.42(3.08)$ & $0-13$ & $61.54(27.02)$ \\
\hline Happy-Distract* & $0.26(0.60)$ & $0-3$ & $9.63(20.84)$ \\
\hline Happy-Self Soothe & $0.23(0.71)$ & $0-3$ & $4.16(9.88)$ \\
\hline Happy-Play Activity & $0.10(0.65)$ & $0-5$ & $1.25(5.36)$ \\
\hline Happy-Talk* & $0.98(1.67)$ & $0-8$ & $22.08(20.42)$ \\
\hline Sadness-Defiance & $0.03(0.18)$ & $0-1$ & $2.82(16.05)$ \\
\hline Sadness-Problem Solve* & $2.02(2.63)$ & $0-10$ & $63.05(29.65)$ \\
\hline Sadness-Distract* & $0.37(0.79)$ & $0-4$ & $12.19(23.62)$ \\
\hline Sadness-Self Soothe* & $0.19(0.51)$ & $0-2$ & $6.13(17.67)$ \\
\hline Sadness-Play Activity & 0 & 0 & 0 \\
\hline Sadness-Talk* & $0.55(1.02)$ & $0-5$ & $16.12(19.05)$ \\
\hline Anger-Defiance & $0.03(0.18)$ & $0-1$ & $0.38(1.96)$ \\
\hline Anger-Problem Solve* & $5.06(4.22)$ & $0-15$ & $80.51(24.44)$ \\
\hline Anger-Distract* & $0.29(0.69)$ & $0-3$ & $6.06(17.67)$ \\
\hline Anger-Self Soothe & $0.10(0.35)$ & $0-2$ & $1.20(4.25)$ \\
\hline Anger-Play Activity & 0 & 0 & 0 \\
\hline Anger-Talk* & $1.16(1.85)$ & $0-8$ & $11.85(14.31)$ \\
\hline Anxiety-Defiance & 0 & 0 & 0 \\
\hline Anxiety-Problem Solve* & $0.44(1.43)$ & $0-10$ & 83.75 (22.09) \\
\hline Anxiety-Distract & $0.03(0.18)$ & $0-1$ & $3.13(7.93)$ \\
\hline Anxiety-Self Soothe & 0 & 0 & 0 \\
\hline Anxiety-Play Activity & 0 & 0 & 0 \\
\hline Anxiety-Talk* & $0.15(0.72)$ & $0-5$ & $13.13(21.74)$ \\
\hline
\end{tabular}

Note. Emotion-Action sequence percentages are out of total display for each emotion category

$*=$ emotion-action sequences used in regression analyses 


\begin{tabular}{|c|c|c|c|c|c|c|c|c|c|c|c|c|}
\hline \multirow[b]{3}{*}{ Predictors } & \multicolumn{12}{|c|}{ Emotions } \\
\hline & \multicolumn{4}{|c|}{ Step 1} & \multicolumn{4}{|c|}{ Step 2} & \multicolumn{4}{|c|}{ Final Step } \\
\hline & $\mathbf{R}^{2}$ & $\mathbf{B}$ & SE & $95 \% \mathrm{CI}$ & $\Delta \mathbf{R}^{2}$ & B & SE & $95 \% \mathrm{CI}$ & $\Delta \mathbf{R}^{2}$ & B & SE & $95 \% \mathrm{CI}$ \\
\hline & \multicolumn{8}{|c|}{ Happiness } & & & & \\
\hline & .00 & & & & .02 & & & & .02 & & & \\
\hline Total Family Income & & .00 & .02 & $-.04, .04$ & & .01 & .02 & $-.03, .06$ & & .01 & .02 & $-.04, .06$ \\
\hline Emotion Dysregulation & & & & & & $<.01$ & $<.01$ & $<-.01,<.01$ & & $<.01$ & $<.01$ & $<-.01,<.01$ \\
\hline Maternal Supportive Responses & & & & & & & & & & -.01 & .01 & $-.03, .02$ \\
\hline \multirow[t]{3}{*}{ Maternal Non-Supportive Responses } & & & & & \multirow{2}{*}{\multicolumn{4}{|c|}{ Sadness }} & & -.01 & .01 & $-.03, .01$ \\
\hline & & & & & & & & & & & & \\
\hline & .00 & & & & $.12 * *$ & & & & .04 & & & \\
\hline Total Family Income & & $<.01$ & .02 & $-.03, .03$ & & .02 & .02 & $-.01, .05$ & & .02 & .02 & $-.02, .05$ \\
\hline Emotion Dysregulation & & & & & & $<.01 * *$ & $<.01$ & $<.01,<.01$ & & $<.01 * *$ & $<.01$ & $<.01,<.01$ \\
\hline Maternal Supportive Responses & & & & & & & & & & -.01 & .01 & $-.03,<.01$ \\
\hline \multirow[t]{3}{*}{ Maternal Non-Supportive Responses } & & & & & \multirow{2}{*}{\multicolumn{4}{|c|}{ Anger }} & & -.01 & .01 & $-.03,<.01$ \\
\hline & & & & & & & & & & & & \\
\hline & $.08^{*}$ & & & & .03 & & & & .05 & & & \\
\hline Total Family Income & & $-.06^{*}$ & .02 & $-.11,-.01$ & & $-.07 * *$ & .03 & $-.13,-.02$ & & $-.07 * *$ & .03 & $-.12,-.02$ \\
\hline Emotion Dysregulation & & & & & & $<-.01$ & $<.01$ & $-.01,<.01$ & & $<-.01$ & $<.01$ & $-.01,<.01$ \\
\hline Maternal Supportive Responses & & & & & & & & & & .02 & .01 & $-.01, .05$ \\
\hline \multirow[t]{3}{*}{ Maternal Non-Supportive Responses } & & & & & \multirow{2}{*}{\multicolumn{4}{|c|}{ Anxiety }} & & .02 & .01 & $<-.01, .04$ \\
\hline & & & & & & & & & & & & \\
\hline & .05 & & & & .01 & & & & .03 & & & \\
\hline Total Family Income & & .02 & .01 & $<-.01, .04$ & & .02 & .01 & $-.01, .04$ & & .02 & .01 & $-.01, .05$ \\
\hline Emotion Dysregulation & & & & & & $<-.01$ & $<.01$ & $<-.01,<.01$ & & .00 & $<.01$ & $<-.01,<.01$ \\
\hline Maternal Supportive Responses & & & & & & & & & & .01 & .01 & $<-.01, .02$ \\
\hline \multirow[t]{3}{*}{ Maternal Non-Supportive Responses } & & & & & \multirow{2}{*}{\multicolumn{4}{|c|}{ Neutral }} & & $<.01$ & .01 & $-.01, .01$ \\
\hline & & & & & & & & & & & & \\
\hline & .04 & & & & .01 & & & & .01 & & & \\
\hline Total Family Income & & .04 & .03 & $-.01, .10$ & & .04 & .03 & $-.01, .10$ & & .03 & .03 & $-.03, .09$ \\
\hline Emotion Dysregulation & & & & & & $<-.01$ & $<.01$ & $<-.01,<.01$ & & $<-.01$ & $<.01$ & $-.01,<.01$ \\
\hline Maternal Supportive Responses & & & & & & & & & & -.01 & .02 & $-.05, .02$ \\
\hline Maternal Non-Supportive Responses & & & & & & & & & & $<-.01$ & .01 & $-.03, .02$ \\
\hline
\end{tabular}
$*=p<.05, * *=p<.01$

Bolded values are those significant following Bonferroni correction to $p<.01$ 
Table 4

Hierarchical Regressions Predicting Regulatory Behaviors from Maternal Variables

\begin{tabular}{|c|c|c|c|c|c|c|c|c|c|c|c|c|}
\hline \multirow[b]{3}{*}{ Predictors } & \multirow{2}{*}{\multicolumn{4}{|c|}{ Step 1}} & \multicolumn{4}{|c|}{ Regulatory Behaviors (Actions) } & & & & \\
\hline & & & & & \multicolumn{4}{|c|}{ Step 2} & \multicolumn{4}{|c|}{ Final Step } \\
\hline & $\mathbf{R}^{2}$ & B & SE & $95 \% \mathrm{CI}$ & $\Delta \mathbf{R}^{2}$ & B & SE & $95 \% \mathrm{CI}$ & $\Delta \mathbf{R}^{2}$ & B & SE & $95 \% \mathrm{CI}$ \\
\hline & \multicolumn{8}{|c|}{ Defiance } & & & & \\
\hline Total Family Income & & $<-.01$ & $<.01$ & $-.01,<.01$ & & -.01 & $<.01$ & $-.01,<.01$ & & -.01 & $<.01$ & $-.01,<.01$ \\
\hline Emotion Dysregulation & & & & & & .00 & .00 & $<-.01,<.01$ & & $<.01$ & $<.01$ & $<-.01,<.01$ \\
\hline Maternal Supportive Responses & & & & & & & & & & $<.01$ & $<.01$ & $<-.01, .01$ \\
\hline \multirow[t]{3}{*}{ Maternal Non-Supportive Responses } & & & & & & & & & & $.01 * *$ & $<.01$ & $<.01, .01$ \\
\hline & & & & & \multicolumn{4}{|c|}{ Problem Solve } & & & & \\
\hline & .01 & & & & $.10^{*}$ & & & & .03 & & & \\
\hline Total Family Income & & .02 & .021 & $-.02, .06$ & & $<-.01$ & $<.02$ & $-.05, .04$ & & $<-.01$ & $<.01$ & $-.04, .04$ \\
\hline Emotion Dysregulation & & & & & & $<-.01 *$ & $<.01$ & $-.01,<.01$ & & $<-.01 *$ & $<.01$ & $-.01,<.01$ \\
\hline Maternal Supportive Responses & & & & & & & & & & $<.01$ & .01 & $-.02, .02$ \\
\hline \multirow{3}{*}{ Maternal Non-Supportive Responses } & & & & & & & & & & -.01 & .01 & $-.03, .01$ \\
\hline & & & & & \multicolumn{4}{|c|}{ Distraction } & & & & \\
\hline & .01 & & & & .04 & & & & .05 & & & \\
\hline Total Family Income & & .01 & .01 & $-.01, .04$ & & .02 & .01 & $-.01, .05$ & & .02 & .01 & $-.01, .04$ \\
\hline Maternal Supportive Responses & & & & & & & & & & -.01 & .01 & $-.02, .01$ \\
\hline \multirow[t]{3}{*}{ Maternal Non-Supportive Responses } & & & & & & & & & & $<.01$ & .01 & $-.01, .01$ \\
\hline & & & & & \multicolumn{4}{|c|}{ Self-Soothe } & & & & \\
\hline & .03 & & & & .09 & & & & .01 & & & \\
\hline Total Family Income & & -.01 & .01 & $-.02,<.01$ & & $<-.01$ & .01 & $-.01, .01$ & & $<-.01$ & .01 & $-.01, .01$ \\
\hline Emotion Dysregulation & & & & & & $<.01^{*}$ & $<.01$ & $<.01,<.01$ & & $<.01 *$ & $<.01$ & $<.01,<.01$ \\
\hline Maternal Supportive Responses & & & & & & & & & & $<-.01$ & $<.01$ & $-.01,<.01$ \\
\hline \multirow[t]{3}{*}{ Maternal Non-Supportive Responses } & & & & & & & & & & $<-.01$ & $<.01$ & $-.01,<.01$ \\
\hline & & & & & \multicolumn{4}{|c|}{ Play Activity } & & & & \\
\hline & .04 & & & & $.07 *$ & & & & $.08 \dagger$ & & & \\
\hline Total Family Income & & -.01 & $<.01$ & $-.01,<.01$ & & $<-.01$ & $<.01$ & $-.01,<.01$ & & $<-.01$ & $<.01$ & $-.01, .01$ \\
\hline Emotion Dysregulation & & & & & & $<.01 *$ & $<.01$ & $<.01,<.01$ & & $<.01 * *$ & $<.01$ & $<.01,<.01$ \\
\hline Maternal Supportive Responses & & & & & & & & & & $<.01 *$ & $<.01$ & $<.01, .01$ \\
\hline Maternal Non-Supportive Responses & & & & & & & & & & $<.01$ & $<.01$ & $<-.01,<.01$ \\
\hline
\end{tabular}

Talk 


\section{MOTHER-PRESCHOOLER EMOTION REGULATION}

\section{.01}

Total Family Income

Emotion Dysregulation

$-.01$

.01

$-.04, .02$

.02

Maternal Supportive Responses

Maternal Non-Supportive Responses

$*=p<.05, * *=p<.01$

Bolded values are those which remain significant following Bonferroni correction to $p<.008$ $\begin{array}{lll}-.01 & .02 \quad-.04, .03\end{array}$

$<.01<.01<-.01,<.01$

$<.01 \quad .01 \quad-.01, .02$

$.01 \quad .01 \quad-.01, .02$ 
Table 5

Hierarchical Regressions Predicting Emotion-Action Sequences from Maternal Variables

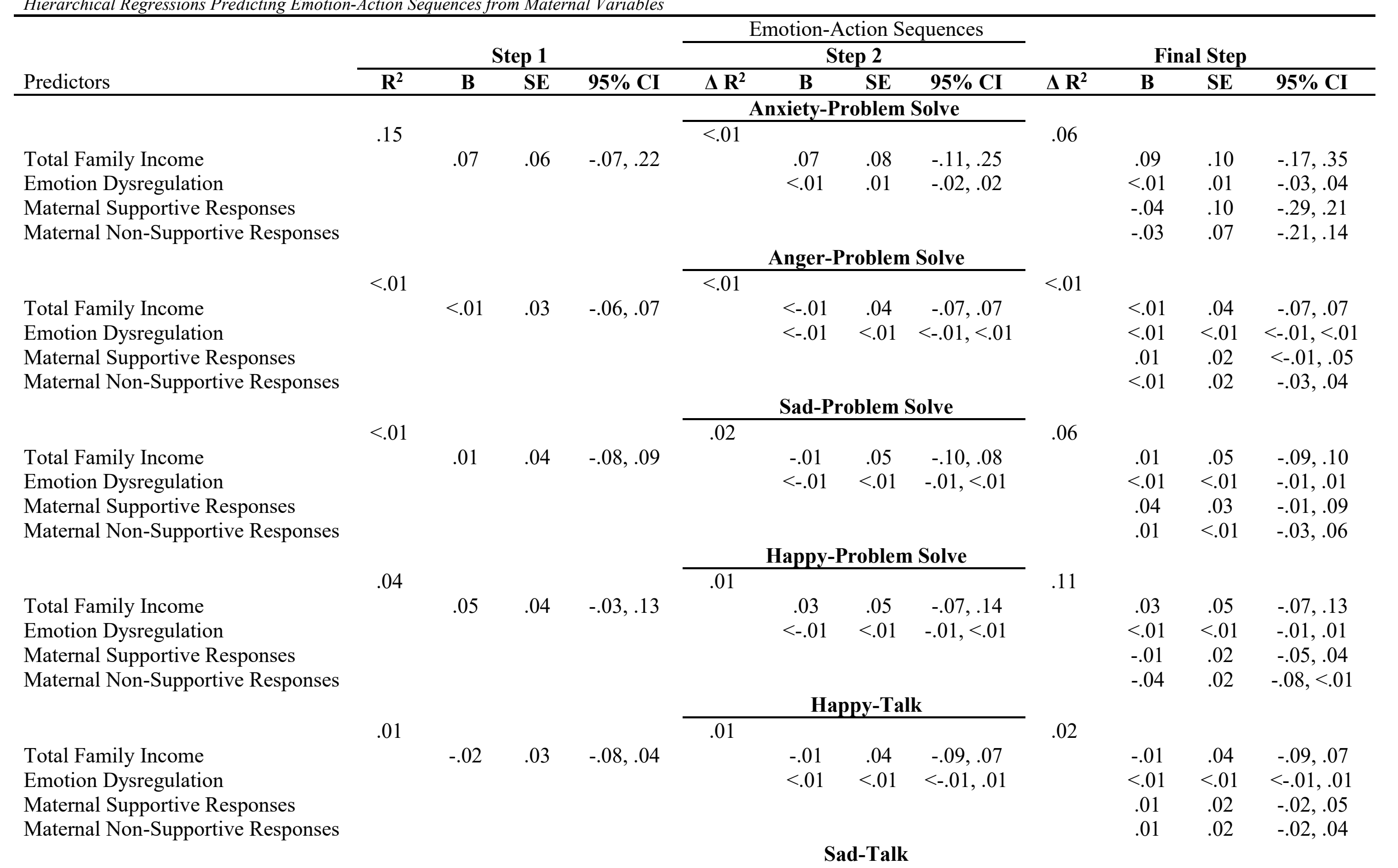


$<.01$

Total Family Income

Emotion Dysregulation

$.01 \quad .03 \quad-.05, .06$

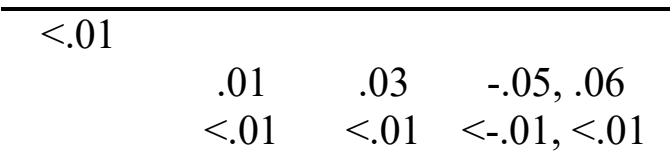

Maternal Supportive Responses

Maternal Non-Supportive Responses

Total Family Income

Emotion Dysregulation

Maternal Supportive Responses

Maternal Non-Supportive Responses

Total Family Income

Emotion Dysregulation

Maternal Supportive Responses

Maternal Non-Supportive Responses

Total Family Income

Emotion Dysregulation

Maternal Supportive Responses

Maternal Non-Supportive Responses

Total Family Income

Emotion Dysregulation

Maternal Supportive Responses

Maternal Non-Supportive Responses

Total Family Income

Emotion Dysregulation

Maternal Supportive Responses

Maternal Non-Supportive Responses
.28

$\begin{array}{lll}-.10 & .06 & -.23, .03\end{array}$

.03

$\begin{array}{lll}.03 \quad .03 & -.03, .10\end{array}$

.01

$\begin{array}{lll}-.01 & .02 & -.05, .03\end{array}$

$\begin{array}{lll}-.01 & .03 & -.07, .06\end{array}$

\begin{tabular}{cccc}
\multicolumn{4}{c}{ Happy-Distraction } \\
\hline$<.01$ & & & \\
& -.02 & .04 & $-.10, .07$ \\
& $<-.01$ & $<.01$ & $-.01,<.01$
\end{tabular}

.03 $\begin{array}{lll}-.02 & .02 & -.07, .03\end{array}$

\begin{tabular}{cccc}
\multicolumn{4}{c}{ Sad-Distraction } \\
\hline $.14^{*}$ & & & \\
& .06 & .03 & $<-.01, .13$ \\
& $<.01 *$ & $<.01$ & $<.01, .01$
\end{tabular}

Anger-Talk

\begin{tabular}{cccc}
\multicolumn{4}{c}{ Anger-Talk } \\
\hline$<.01$ & & & \\
& -.02 & .02 & $-.06, .03$ \\
& $<.01$ & $<.01$ & $<-.01,<.01$
\end{tabular}

.05

\begin{tabular}{llll}
\multicolumn{4}{c}{ Anxiety-Talk } \\
\hline .01 & & & \\
& -.09 & .07 & $-.25, .07$ \\
& $<.01$ & .01 & $-.02, .02$
\end{tabular}

.19

$\begin{array}{ccc}-.12 & .08 & -.33, .09 \\ <-.01 & .01 & -.03, .02 \\ .09 & .08 & -.11, .28 \\ .05 & .05 & -.09, .19\end{array}$

.05

$\begin{array}{ccc}.06 \dagger & .04 & -.01, .13 \\ <.01 \dagger & <.01 & <-.01, .01 \\ -.02 & .02 & -.06, .02 \\ -.02 & .02 & -.05, .01\end{array}$

$-.01 \quad .02 \quad-.06, .03$

$<.01<.01<-.01,<.01$

$.02 \quad .01 \quad-.01, .04$

$\begin{array}{lll}.01 & .01 \quad-.01, .03\end{array}$

.10

$\begin{array}{ccc}-.01 & .04 & -.09, .07 \\ <-.01 & <.01 & -.01,<.01 \\ -.01 & .02 & -.04, .03 \\ .02 & .02 & -.01, .05\end{array}$

.11
Sad-Self Soothe

$\begin{array}{lll}-.02 & .03 \quad-.08, .03\end{array}$

$<.01<.01<-.01,<.01$
$<-.01 \quad .03 \quad-.06, .05$

$<.01<.01<-.01, .02$

$.02 \dagger \quad .01 \quad-.01, .05$

$\begin{array}{lll}-.01 & .01 & -.03, .02\end{array}$

\section{Anger-Distraction}




\section{MOTHER-PRESCHOOLER EMOTION REGULATION}

.01

Total Family Income

Emotion Dysregulation

.02

.02

$-.03, .06$

$<.01$

Maternal Supportive Responses

Maternal Non-Supportive Responses

$*=p<.05, * *=p<.01$

Bolded values are those which remain significant following Bonferroni correction to $p<.006$ 